\title{
Integration Strategy of Entrepreneurial Enterprises Resources
}

\author{
Zhirun Xiao \\ School of Economics \& Management, Shanghai Second Polytechnic University, Shanghai, China \\ Email: xzrun0213@163.com
}

Received May 2014

\begin{abstract}
If venture enterprises rise rapidly, realizing the goal of increment and appreciation, then they must possess strategic concept of resources integration. Meanwhile, venture enterprises have to master and utilize the integrated strategy. This article tries to present the necessity of proceeding of the resources integration among those venture enterprises, and the content and characteristics of entrepreneurial resources integration, followed by a deeper analysis of integration strategy in different types and related problems. At last, the author analyzes the misunderstanding that can be easily made during the process of implementation the integration strategy, and put forward some countermeasures.
\end{abstract}

\section{Keywords}

\section{Venture Enterprise, Resources Integration, Strategy}

\section{Introduction}

Resource is a general term of what an enterprise owns and commands in physical assets and non physical assets. It is the set of the elements and interrelation between production and management. It is not only a set of independent resources, but is a set formed among the different resources within enterprises.

More or less, a venture enterprise has some certain resources. In general, however, most of the resources are scarce. Although the appreciation can be realized bit by bit, it is a way too slow for such enterprises to develop. To get the appreciation of enterprise resources quickly, entrepreneurs need to have a good command of a strategic concept about resources integration, as well as the method to integrate the resources. Integration is a process that various factors of production and venture (mutually related among the system) realize the new permeation, correlation and coordination through multiple of expanding resources channels.

Integration is the demand of enterprise competition, and the premise to venture and develop the strength to meet the competition, the confidence to face the challenge, and a complementation of resources. It is the emphasis for an enterprise to master and command the integrated strategy for the rapid development [1].

\section{The Necessity of Integration Enterprises' Resource}

For any enterprise, their resources are scarce. Then new resources should be increased and supplemented, be- 
cause the scarce resources often lead to an unachieved career.

An enterprise starting a business is not only to obtain incremental source of wealth, but also to turn the knowledge resources into wealth. Under the condition of market economy, any resource is valuable. To obtain these resources, we cannot only rely on the work with honesty, but on the ability to value and exploit the resources. Today, with the economic globalization and information sharing, an important measure to enhance the ability of value development is the integration. Integration makes the scattered resources into integrated resource. It makes the local advantage into the overall advantages. It makes the incomplete information into complete information. It makes visible business opportunities into real business opportunities. It makes the fancy wealth into the gotten wealth. Therefore, this ability to acquire additional resources has become an ability for a person or an enterprise to develop—an ability to get rich.

\subsection{Entrepreneurial Enterprises Need to Obtain the Rapid Development of Appreciation through Integration}

It has been found that the rapid rise of enterprises is the effect of integration of various elements. Entrepreneurship needs a variety of appreciation. These elements need to be obtained through multifarious channels to "integrate". Therefore, earning various needed scarce resources and appreciations make it an effective way to expand the enterprise quickly through many means of integration. These appreciations will let the enterprise take chance to develop and enhance the competitiveness as soon as possible.

\subsection{Integration will Promote Combat Capability of Enterprises' Capital Operation}

The main tool for capital expansion among enterprises is integration. Capital operation is the tool of industry integration. It is the capital market that makes the enterprises to gain funds of industry integration rapidly. Then, their vision of integration industrial can be realized; and using the capital operation to take methods, like procurements and reorganizations, thus, achieving the right to control and operate the industry integration quickly.

Under a relatively perfect economic environment, enterprise merger will be a long-term phenomenon. For example, different resources among many industries integrate and merger every year in USA and the property has been in a state of fluxion. It is this property fluxion, seeking and obtaining a value-added capital that bring rich profit for the enterprises and create values and rewards for shareholders.

\subsection{Integration Has Become Strategic Ability of Multinational Corporations to Obtain Maximum Profit}

The concept of globalization demands enterprises to evaluate the merits and demerits of the market competition strategy through a global perspective and the development of market. Under the new situation of global economic integration, the Multinational Corporations' production and management have undergone significant, strategic adjustment.

This adjustment has two obvious characters.

One is the integration of global production. It refers to that the Multinational Corporations will no longer rely on capital, scale, nor geographical advantages to organize production, but trying to integrating factories established around the world ted into a coherent whole. They will not go back to concentration the manufacture, or sticking to inherent pattern of decentralized organization. But they will make full use of special effects of network in the system on the integration of production to establish a dynamic, open and agile network system to realize the integration of productive resources.

Another character is the integration of global marketing resources. It is the superiority of Multinational Corporations utilizing the network that turns the past raw materials and product sales through the regional procurement into the global procurement of raw materials and product sales. Thus, they can perform raw materials in the global scope, as well as carrying out the development of market in the global scope.

The change of the Multinational Corporations' strategy explains that the reality and possibility that network provides for integration of multiple resources, and explains that it is a new method for enterprises to chase the space of maximizing profits through the resources integration of various factors of production and marketing elements under the new situation of global economic integration. 


\section{The Content and Characteristics of Enterprise Resources Integration}

\subsection{The Content of Enterprise Resources Integration}

\subsubsection{The Integration of Internal Resources and External Resources}

In the process of the development of a venture enterprise, the enterprise's internal resources are often insufficient or even scanty. This situation leads to absorbing and supplementing the necessary external resources - that is the demand of integration of internal and external resources. Sometimes, it needs the integration of extensive, multilateral and external resources integration, so that enterprises can have accurate analysis on a deal or a business. At last, the enterprises can determine and make decisions. For example: H Company prepared using a novel fiber fabric to produce garments. This requires the enterprises to integrate the information they have including resource and product information, such as the testing report of the provision from product testing departments). Then, they are ready for making a real and correct judgment of the performance and characteristics of the product. At last, they can make the decision to order or not by this judgment whether the new fabric really has the superiority.

\subsubsection{The Integration of Market Development and Marketing Planning}

Marketing needs planning. If venture enterprises want to expand the market as soon as possible, they need to integrate the act of expanding the market expectation and marketing in order to achieve better results.

For example: there was a new bean named red bean hybridized by soybean and sweet potato. At the beginning of this new product, the owner made a rough packaging and marketed in the general stores. The effect was not very good. Then the owner found a consulting company. They thought the effect would be good through preliminary planning, packaging and the Internet after analysis. During the planning, planning staffs gave the product a resounding name- -lily bean", and designed an exquisite packaging - 6 pieces of lily would be put in each bag of one kilogram. Red bean, together with white lily, grows more attractive. Coupled with the meaning of lily "a harmonious union lasting a hundred years", they became very popular with people. After designed, they soon put the message to each site in the Chinese and English. And within ten days, 10 tons of products were all sold out.

The above example illustrates, the planning of the wisdom and philosophy will add new vitality to the market marketing, and integrated marketing and marketing will have a significant effect on the market. But it should be pointed out that, the network marketing planning is different from traditional planning. While network focuses on the whole planning process and Omni-direction, traditional planning focuses on ideas and schemes. They not only need to come up with a creative idea, but also to help customers set a plan, and then to determine the plan online until the integration of related resources on the Internet to make effectiveness release.

\subsubsection{Integration of the Methods of Network Marketing and Traditional Marketing}

With the development of computer technology and network information technology, many enterprises have established their own business website (online store) or registered and logged in some of the famous Internet market to launch the online marketing conditions. However, Internet marketing and traditional marketing are needed to be integrated, because network marketing is developed on the basis of traditional marketing. The turning of traditional marketing to the network marketing is gradual, from less to more. In the process of network marketing, the huge customers will not shift to network marketing at once, nor even possible. There must be a two-way parallel period. During this period, enterprises cannot bear to lose this traditional market of customers; moreover, they need to integrate the traditional marketing. Furthermore, the traditional marketing and traditional trading will still be the main channel of certain transactions mode that consuming subject will choose in a certain period of time.

From the process of online transactions, after the negotiation, there can be two optional choices while delivery: online and traditional. It is obvious that online transactions are not as reliable as traditional trade way during the whole network environment at present. Therefore, the seller and the buyer can mutually agree that they can communicate and negotiate online, while using the traditional trading mode of delivery to avoid or reduce transaction risk. As long as this is the real opinion belonging to both parties, can it be chosen completely by the buyers and sellers.

\subsubsection{The Integration of Hot and Cold Information}

Every kind of information resource needs to be integrated in business activities. Only after the integration and 
becoming the incremental resources can they develop the value of information resources. For example: hot and cold information need to be integrated. No matter in the traditional marketing or network marketing, thermal information is often noted while cold information is often neglected. However, there is much available value hidden in cold information. Therefore, in the practice of marketing, they need to integrate the hot and cold information. Sometimes they may have to multi-integrate the resources in order to provide better services for the same business. For example: company $\mathrm{C}$ will buy 4 big cabinets' of miniature Christmas tree with self luminous by mail before Christmas. The company $\mathrm{D}$ has the supply of goods, but none of them is the luminescent material, so they cannot meet the company C's requirements. However, once the company D adds 5 pieces of light emitting beam blade inside the existing Christmas tree leaves can the goods meet the requirements of company C. In this case, it will require enterprises to integrate heat and cold information existing-finding a manufacturer that processes light beam blade company $\mathrm{C}$ needed. Then, they will be able to undertake foreign orders successfully. [2].

\subsection{Features of the Integration of Venture Enterprises' Resource}

\subsubsection{Universality of Integration Demands}

The information of today's society is highly developed, together with perplexing interpersonal relations. To strengthen the enterprises, each department needs to cooperate closely under such social circumstance. It will need more coordination works to have the enterprises' strength enriched, and reaching development goals at last. That is to say, in the era of information economy, it is hard to achieve the goal only by oneself no matter in scientific research, production, invention, nor in business activities. Just like an American scholar, Bean thinks "Industrial society's value is competition and the value of the era of knowledge economy is cooperation". Therefore, the brand new value will become a common pursuit for modern people. It is the universal integration requirements for cooperation that provides the possibility for enterprises to integrate in a variety of resources, a variety of channels and a variety of means [3].

\subsubsection{Complementation of Integration}

Integration is complementary. It can turn the local advantage into the overall advantages; dispersive advantage into the comprehensive advantages; the scarce resources into the rich resources; incomplete information into complete information. This complementation has great utility in venture enterprises. In the entrepreneurial process, a considerable number of enterprises faced with the problems that often lead to the failure of achieving the career, like lacking of funds, information, personnel and other resources. That will need them to enrich and supplement the necessary external resources, using the complementary to make impossible things become possible; to make a deal with those impossible business; to occupy the impossible market. Finally, they will realize complementing various resources and achieve win-win or multi win.

\subsubsection{The Appreciation of Integration}

The appreciation of integration is determined by complementarities of integration. After integration and complementation, many problems impossible to solve are settled and difficult businesses are dealt with, which will certainly produce appreciation effect.

For example, taking market $\mathrm{G}$ as an example. There still are 9 comprehensive web-sites running by telecommunications offices in all districts expect for information port in city G. These sites cannot meet the demand of users because of the small publicity, the repetition of column, the lack of information, and the narrow of scope. Hundreds or thousands of visitors every day results in a waste of resources to a certain extent. G's data center based on the general thinks that "resource integration, jointly with the strong, the pursuit of quality and establishing a brand", to integrate city G's information port and G's windows for two comprehensive network successfully. Thus, we can find a new way for the next step to the development of Telecom website, and inject the new vitality to G's Telecom Integrated site.

Thus it can be seen that the advantage of integration external resource is very obvious, as well as the appreciation of its integration.

Here is a comparative study on the effect of integration of network marketing business information by some institution, as shown in Table 1 [4].

As the comparison on the table, the effect of integration of the information resources or not is quite different in the network marketing. 
Table 1. 100 Business Information published case comparison.

\begin{tabular}{ccccc}
\hline The amount of information & Publishing Web Sites & Integration measures & $\begin{array}{c}\text { the effect before } \\
\text { integration }\end{array}$ & The effect after integration \\
\hline 100 & 181 & 4 & Feedback 2 & $\begin{array}{c}\text { Feedback 17, } \\
\text { Trading success 2 } \\
\text { Feedback 11, } \\
\text { Trading success } 2 \\
\text { Feedback 9, } \\
\text { Trading success2 } \\
100\end{array} 157$ \\
100 & 3 & Feedback 3 & 0 & Feedback 7 \\
100 & 141 & 2 & 0 & 0 \\
\hline
\end{tabular}

\section{The Strategic Integration in Different Types and Related Problems}

Strategic integration has various types and methods. And different types or different situation of enterprises have different requirements and priorities.

\subsection{The Strategic Integration in the Process of Production}

There are 3 tips that we should notice in the process of strategic design:

(1) Pay attention to strengthen the weak links. Try to avoid weakness caused by operation or process, thereby, promoting the incremental structure.

(2) Strengthen the control of production process. Form the appreciation in the production process by controlling the "quality control" balance and standard.

(3) Attentions should be paid to solve the problem of lacking of management. Balance the synchronization of control and management of production implement to avoid the situation of lacking of management.

\subsection{The Strategic Integration in Marketing}

The issue need to be considered in integrated marketing is:

(1) The integration of the channels of marketing should form the extension and expansion of channels.

(2) Integrated marketing tools should pay attention to the implicit strategic intents of integration process. To integrate resources while not to explore strategic intents goes one better.

\subsection{The Strategic Integration in Financial Management}

Strategic integration in financial management should focus on the following three aspects:

(1) Seize the main items of the integrated financial management strategy, and lead the weaknesses. Only highlights the main items, together with promoting the weaknesses can demonstrate the effect of integration.

(2) Do make the design of financial management strategy. Attentions should be paid to strengthen financial management, management system implementation, and the real of the basic data. These true, implement compaction and the reality can lay a solid foundation for the integrated financial management after the appreciation.

(3) Make full use of modern information technology. Most of financial management effects are reflected through a variety of digital. Therefore, the strategic integration of financial management should try to use digital to present. Make full use of modern information technology with statistical analysis, and resolve the substantive issues in financial management effectively [5].

\subsection{The Strategic Integration in the Allocation of Human Resources}

Strategic integration of human resource allocation should be noted in the following two points:

(1) Stick to the principle of allocation according to requirement. Don't consume highly for human resources. Any venture enterprises cannot bear the sinking of human resources. The sinking will form the waste of human resources.

(2) Pay attention to balance the allocation and appropriate of integrated human resources. 


\section{Problems Should Notice in Implementing the Strategic Integration}

\subsection{Guard against Formalism}

The formalism in integration is unacceptable. Some enterprises engage in strategy of "big and complete", attempting to have a considerable number of enterprises integrated in their own house, and to be the bellwether of industry. However, the effects are often greatly disappointing. This integration does not analyze their respective advantages and characteristics, but only pull up a batch of enterprises in form. It does not reflect the real need of development and the inherent power. The effect is imaginable for having fancy formalism.

\subsection{Avoid Blind Expansion}

This happens frequently in integration that some enterprises do not have strategic thinking, indiscriminate, and site integration blindly to expand the scale. Since there is no clear profit point, the size of the scale is rising on the contrary of benefit. This is the misunderstanding of blind expansion.

\subsection{Avoid Seemingly Harmonious}

Another typical manifestation of integration is seemingly harmonious. The fusion needs time especially because of the different culture between enterprise integrating and integrated. This difference is particularly evident in the early stage of fusion. For an enterprise, the core competitiveness is the centripetal force and cohesion of the team. It can often be seemingly harmonious if lacking of this core, even integrate the enterprise. That is what a venture enterprise should avoid and prevent in the implementation of strategic integration.

\section{Acknowledgements}

This article is funded by Management Science and Engineering, Shanghai Second Polytechnic University, No. XXKPY1313.

\section{References}

[1] Ireland, R.D., Hoskisson, R.E. and Hitt, M.A. (2013) The Management of Strategy: Concepts and Cases. 10e, 66-68, 334-339

[2] David, F.R. (2011) Strategic Management: Concepts and Cases, Global Edition. 13th Edition, Pearson Education, Inc., Upper Saddle River, 235-240.

[3] Morse, E.A. and Mitchll, R.K. (2006) Cases in Entrepreneurship by Sage Publications, Inc., 218-222.

[4] Wang, R.L. (2005) Entrepreneurship Strategy Design. Tsinghua University Press, Beijing, 214-216.

[5] Bosma, N., Acs, Z.J., Autio, E., et al. (2009) Global Entrepreneurship Monitor. 2008 Executive Report, Babson University Press, Boston, 125-128. 